\title{
Analyzing Phenomenological Descriptions ${ }^{1}$
}

\section{Loren Barritt}

University of Michigan

Ton Beekman, Hans Bleeker and Karel Mulderij

University of Utrecht

The analysis of written material is a formidable task for the phenomenological researcher. In this article we describe one way to help students begin.

We start by choosing a topic on which everyone can write. "Being left out," "Falling asleep," "A favorite childhood play place," or "Being afraid in the dark" are all successful topics we have used. After selecting the topic we ask everyone to write a short, one or two page, description about it for the following class meeting. Three or four people are asked to reproduce their descriptions for the entire group to read. With these descriptions the analysis begins.

At the start of the session we choose one of the reproduced descriptions and everyone takes a moment to read it. Since everyone has already written an account, the reading of this first text is already a comparison. As we read we look for themes. These are inevitably the result of a comparison with our own views. It is exciting to see intersubjective agreement appear as the subjective experience of "waking up," or "being afraid in the dark" is found to have shared qualities.

Our sessions usually consist of several weeks of joint analysis coupled with readings from the phenomenological literature. In this way phenomenology is introduced not as philosophy but as a way of doing.

Working in a group, at least at the start, is an advantage because in the effort to achieve understanding a consensus must be reached. This illustrates, vividly, the effort required to achieve an accurate restatement of what appears to be a common theme. After working together for a quarter of an hour on the correct descriptions of an experience it is maddening to have your informant reject your effort. "No, that's not what it is like for me. It may be like that for you, but not me. I..." Sometimes this leads to a more precise formulation of a shared experience, sometimes to the recognition that something unique is being described. The frustration is usually relieved with some better understanding. Sessions are not dull and time goes quickly; there are themselves good examples of the intersubjective experience. 
What we propose to do in this article is "walk through" the procedures we've just outlined, giving advice as we go along. We'll imagine that we are working with a group you belong to and use as example one of the topics from a previous seminar.

\section{Afraid in the Dark}

We will begin with an old chestnut, something that we have used numerous times to begin talking about written description. Before going on to read the examples we urge you to write a description of a time when you were afraid in the dark. Don't worry about how it's done, what to include, and what not to include. It is only necessary that you have something which you can compare to the following examples. Read Suggestion I and then begin.

Suggestion I: Write an account of a single experience, something simple and straightforward; as much as possible stick to descriptive language and watch out for interpretations and attributions of causality in your writing. Don't lose yourself in factual details. It all begins with the lived experience and that is what you should strive to describe.

\section{Afraid in the Dark I}

The last time I was afraid in the dark is long ago. That time I had to go from a nearby village to walk home, where the path went through a woods. It was understood beforehand that I was supposed to be home before it got dark, but because of the insistence of my host that didn't happen. Now I had to pay for that ... I imagined the whole way home in my thoughts ... which places were the most "dangerous."

What was still being said hardly made an impression. I was asked questions and gave superficial answers. My thoughts were elsewhere.

When I finally left it was almost dark. After a short time I arrived at the entrance to the wood and then it was even darker and more menacing than I had expected. I tried not to attract attention at the same time looking for the best way in, trying to make as little noise as possible. Sometimes I stepped on a twig that I hadn't seen and then I was stung through with fright. I huddled up and looked carefully behind and alongside to see what was there... It seemed to be nothing and that gave me courage to overcome the fear. I spoke to myself saying things like ... "Don't imagine such things ... Don't make yourself so anxious" ... but it was little help. It was as if someone else spoke to me, therefore it was of little help. Suddenly I was terrified again. What is that ... A noise ... your breathing stops, you feel small, insignificant, anxious; your knees shake. Later I found out it was a bird flying out of a tree, probably an owl. I often caught myself going faster, at the same time I realized it and slowed down. It was all too crazy. At the same time I kept my eyes and ears open; you never can know. As I got closer to some bushes I crossed over the path and made a big detour around them. Your hands get clammy. What a relief it was when I got past there. At one place I thought I saw someone standing, my foot refused . . . then I saw that it was a mistake. Lucky that ...

It seemed to take me a long time. Was it so far? Usually you walk that path alot faster. Now it seemed endlessly long. One more turn and finally I'm out of the woods. Money couldn't get me to go back. 
This is a good example of a written description. You get a good feel for the experience and it brings back memories. We have all had the same kinds of experiences and we recognize the feelings the text draws out. This drawing out by the text of shared feelings is an example of the intersubjective experience.

Below is another example.

\section{Afraid in the Dark II}

When I go home from work in the evenings usually I take the short cut. The short cut definitely saves me 10 minutes. I then leave the well-lit state road and ride toward a dark unlit empty street.

The dark street with high steep hills lying on both sides, a gaping mouth for me. I give myself in there with a feeling of anxiety and uncertainty. As soon as the last lightpole and the last house is lost behind me I feel myself enclosed in the darkness. The dark completely envelopes you and is everywhere. You feel anxious about something that doesn't show itself. It is different than, for example, being afraid of a dog. You know the dog and you can defend yourself by taking a big stick or by choosing another path. The dark is another enemy. It imposes on you from all sides, without your knowing precisely where the danger comes from.

While I hurry along the dark street I narrow my pupils and sharpen my ears trying to identify every sound. Whenever I succeed in identifying a sound it puts me at ease: that is a frightened bird who flies away, that is the wind that whistles in the tree tops. Identifying sounds and naming them puts me at ease.

But no matter how I narrow my pupils and sharpen my ears there is my back which is unguarded. From behind I am vulnerable but I still don't look. By harder pedaling on my bike I try to protect my unguarded rear. I ride on and stay alert.

Then suddenly I'm frightened. I feel a paralysis go through my limbs; is there someone standing there? It is a form, a human figure. When I approach I'm relieved, it is nothing, it is only a bush. I'm disposed to immediately recognize a figure. And the worst thing that apparently can happen to me is to meet a person here. If I meet someone here I shall watch him carefully from my bike and keep my eye on him, I can't do anything else but mistrust him. Anyone who is wandering around here so late cannot have very good intentions.

In the distance looms the first light pole again and I see the glow from the first houses. I take a deep breath and a feeling of relief overcomes me. I slow the pace of my pedaling. Looking behind now, the darkness recedes.

If I meet someone now, I am no longer afraid. I'll look at him and say "good evening," even if I don't know him.

These two accounts were independently written yet some similarities between them are readily apparent. We hope you see them, and also similarities between them and what you have written.

Here is one more account.

\section{Afraid in the Dark III}

The word "dark" has in our language usage a certain ominous meaning; "dark times," that has a dark look to it, etc. Also the "sound coloring" of the word has something menacing about it. 
In a lot of cultures dark has this meaning. Compare for example the story of Genesis where light is good, in contrast to the dark which has something bad about it.

The form and the amount of fear shown by people for the dark differs by culture (in cultures where there is no electricity people protect themselves from the dark, for example, through offerings and dances, we turn the light on) and by individual; one is more fearful than the other.

The oppressive, ominous character of the dark affects everyone to a greater or lesser extent. In the dark well known things become oppressive, an oppressiveness that surrounds you and cannot be localised. Noise that is unremarkable during the day provokes fear in the still of the night.

The threat, the uncertainty that comes out of the dark is more ominous when one walks alone in the dark than when you "cross" the dark with more people. The knowledge and trust of being with other people makes the power of the dark less fearful.

Compare the three descriptions and see whether you agree with us that the first two are "better" than the third. The third doesn't describe a personal experience of being afraid in the dark. It is written from the outside, from an impersonal point of view. In that sense it isn't a description of lived-through experience.

In the third description we are told that the dark "affects everyone," that some people are more fearful than others, that cultures vary in their treatment of this fear. These things may all be quite true but they do not permit us to understand the feelings, thoughts, and reactions of the person who is fearful when surrounded by darkness. The third description is an example of an analysis without description.

In daily life our common sense informs us sufficiently so we get along nicely. We have little trouble in conversation with friends even about being afraid in the dark. Yes, everyone might agree the dark is like that. For research purposes however it is not enough to leave it at that. We want, as much as possible, to get back to what it is like, for you, for us, when we are having the experience, to bring into awareness what has been taken for granted.

If we ask of the first two descriptions: What is it like, being afraid in the dark, there appear several good answers.

\section{In description I:}

"I was stung through with fright."

"I huddled up and looked carefully behind."

"Your breathing stops."

"You feel small."

In description II:

"I feel myself enclosed in the darkness."

"I feel a paralysis go through my limbs."

One can begin to work with these descriptions. There are also conclusions that the writers have drawn. 
In description I:

"It was as if someone else spoke to me therefore it was of little help."

In description II:

"It is different than for example being afraid of a dog."

Both of these clarifying sentences rest outside of the immediate experience. They do not appear to be the thoughts of that moment but rather thoughts that came later as clarifying, amplifying examples. They are not "wrong," we don't want to suggest that, and they may in fact have been a part of the experience; to know that one would have to ask the writers. This kind of questioning gives a good opportunity for everyone to clarify their understanding of the text and for the writer to try again to say what happened if in fact the original text has inadvertently moved too far off from the experience itself.

\section{The Analysis}

There are innumerable ways to prepare an analysis of written materials, be they descriptions of lived experience, or transcriptions of spoken conversations, or written notes from observations. Perhaps the simplest to work with is the written description of a first-hand experience. We have worked out a step by step procedure that we offer as a starting point for your conduct of an analysis. As we've said elsewhere this procedure is offered because we've found it helpful. It is not a fixed formula and we bend it to fit the information whenever that seems best.

The goal of the analysis is to find common themes in the written descriptions and to find language that captures these themes, or what some prefer to call structures. You might want, before going on, to try identifying the common themes in these three (four with your own) descriptions of "Afraid in the Dark." Then you can compare what you've done and how you've done it with our procedures and results. This can be a check on the reality of the intersubjective moment.

We begin the analysis by going to each description in turn and taking from each, as much as possible in the language used by the informant, what seem to be important elements of the experience. What are the "important" elements? That is for each of us to decide using his or her own experience as a guide. It is at this point that the craft of research begins.

In the conduct of positivistic research individual variations among researchers' judgments ("unreliability") are overcome with the introduction of a multiple-choice test. Such a test might run like this: When you are afraid in the dark how do you feel? (A) That you are all alone (B) That someone is there with you (C) That you mistrust others (D) All of the above. With this form of questioning the differences among analyses are overcome at the start. In phenomenologi- 
cal study as we propose it, however, disagreements are not overcome; in fact, they are a part of the procedure. A central question, left open in the conduct of each study, is whether there is in fact agreement. A negative answer to this question is not a sign that something is wrong, only that what started out as a study of a single experience has become a study of several experiences.

In conducting a thematic analysis it is important to try to read each description with fresh eyes allowing the important moments to step out of the linguistic framework.

Suggestion II: Read through each description and select from it those moments which seem to be at the center of the event for the person. Those moments which "fly up like sparks" from the description. Don't worry about taking too much. Try to read each description with "fresh eyes," anew, letting it speak for itself of the event.

We present below our list of "moments" taken in turn from each of the descriptions.

Forms:

I 1. I imagined the whole way home... which places were most dangerous. My thoughts were elsewhere.

2. Wood: darker, more menacing than expected-looking for best way in.

3. Trying to make as little noise as possible.

4. Stepped on twig-stung with fright.

5. I huddled up.

6. Looked carefully behind and alongside.

7. I spoke to myself-it was little help-it was like someone else spoke to me.

8. A noise, breathing stops, feel small, insignificant, anxious, knees shake.

9. It was a bird, owl (no need for fear).

10. Caught myself going faster.

11. Kept eyes, ears open.

12. Hands get clammy.

13. Relief to be past bushes.

14. Thought I saw someone-mistake (relief).

15. Seemed to take a long time-seemed endlessly long.

16. Money couldn't get me to go back.

II 1. The dark street ... a gaping mouth for me.

2. I give myself in there feeling anxiety, uncertainty.

3. Last lightpole and last house then I feel myself enclosed in the darkness ... it is everywhere.

4. Anxious about something ... doesn't show itself.

5. I hurry along.

6. I narrow pupils, sharpen ears trying to identify every sound.

7. Whenever I succeed in identifying a sound it puts me at ease: that is a bird, that is wind.

8. There is my back, unguarded.

9. From behind I am vulnerable but I still don't look.

10. Harder pedaling ... protect rear. 
11. I ride... stay alert.

12. Frightened ... paralysis through limbs ... is someone standing there?

13. Approach ... relieved ... it is nothing.

14. Worst ... meet person here ... mistrust ... cannot have good intentions.

15. First light pole, glow, houses, deep breath and relief overcomes me. Slow pace.

16. Look behind now-darkness recedes.

17. If I met someone now, I am no longer afraid.

III 1. The oppressive, ominous character of the dark.

2. It surrounds you.

3. Noise ... provokes fear.

4. Uncertainty comes out of the dark.

5. More ominous when one walks alone.

As we go through this step we use each person whose description is being scrutinized as the expert. As "moments" are chosen and written the "expert" is encouraged to comment on or to correct any misstatement of his or her intentions. Often themes are not found in the words of the description but between the lines. In these cases it is important that the choice of words be "correct."

In research conducted away from one's informants it is difficult to correct misunderstandings. In these studies it is a good idea to ask informants to read through the analysis before it is in final form. An informant does not have the right of veto over your insights, but his comments may lead to a more accurate formulation or to the insertion of a paragraph explaining that your insights were not seconded.

Now that we have made a preliminary selection of "forms" in the words used by the informants we need to compare them with one another to make a list of shared themes. It is in this way that we can come to a decision about the shared aspects of the experience. Once again we would urge you to try making your own list before seeing what we came up with. There is no right or wrong about any of this. We are trying to use our language to understand and appreciate the meaning of experience for other people. Some do that more insightfully than others. We claim no special powers.

\section{Themes or common forms:}

1. Anxiety beforehand (I-1; II-2)

2. Darkness is enveloping, surrounds you (I-2; II-1, 2, 3; III-2)

3. Unidentified noise is frightening, identification reduces fear-relief (I-4, 8, 9; II-6, 7, 9; III-3)

4. Imagine seeing things, other people and they are not trusted, identification reduces fear (I-14; II-12, 13, 14)

5. Go faster, hurry up (I-10; II-5, 10)

6. Heightened awareness, try to listen and watch more carefully (paradox: frightened by hearing and seeing, see 3 . and 4. above) (I-3, 6,11 ; II-6, 11)

7. Behind you is unprotected (I-6; II-8, 9, 10)

8. Relief from anxiety, uncertainty, to be back in light, among people (I-13, II-15, 16, 17) 
We have been perhaps a bit more careful here than we usually are when we do an analysis for ourselves, but then we probably make mistakes by jumping too quickly from the written account to the statement of a common theme. After each theme we have listed the statements from the initial list which lead to our judgment. In the beginning and certainly when working as a group that is probably a good idea.

In working with more written descriptions the researcher should, after analyzing a few, turn to accounts written by other informants to see what might be missing from the list of themes. To integrate these accounts with those examined earlier, all that will be needed in most cases is a rewording of a theme based upon some further clarification. When a group of people are working together, this step is unnecessary because each person has been able to test the theme formulation against his or her own experience.

In making a search for common themes one almost always comes across unique themes. We call these "variations" in the themes and list them separately. As the analysis goes on there is a continual movement back and forth from text to theme statements, and movement of themes into the variation category or vice versa. As new material is added, original, tentative decisions are changed in favor of more accurate formulation. It isn't a flawless procedure but it is systematic. There can be a feeling of exhilaration after a difficult struggle if one has achieved the "right" formulation and a better understanding.

\section{Variations:}

1. Try to make yourself small-feel insignificant.

2. Don't look behind.

3. Talk to yourself-it doesn't help.

3. It takes longer.

Suggestion III: Compare the themes you have chosen with one another. Make a list of shared themes. Try to be careful to formulate the common forms or themes in a way that is faithful to descriptions. Make a separate list for unique variations on the themes. Variations frequently highlight the meaning of the common forms. (See Table 1)

\section{The Variation}

If we look at the variations we can see that they throw the meanings of the common forms into relief. To feel oneself small and insignificant is to make the darkness seem even larger and more enveloping. Smallness of self is not a contradiction of the theme, it actually reinforces it.

The slow movement of time is a complement to the theme of hurrying up. It is a paradox of this experience that you try to hurry along to escape fear and yet everything seems to take longer. Another paradox is the fear that someone or something is behind, yet you 


\section{TABLE I}

Being Afraid in the Dark

SHARED THEMES/

THEME STATEMENTS

VARIATIONS

COMMON FORMS

1. Anxiety

Beforehand
I-1 I imagined the whole way home ... which places were most dangerous

II-2 I give myself in there feeling anxiety
2. Darkness is enveloping
I-2 Wood: darker, more menacing than expected-looking for best way

II-1 The dark street . . . a gaping mouth for me.

II-2 I give myself in there

II-3 ... then I feel myself enclosed in the darkness ... it is everywhere

III-2 It surrounds you
3. Unidentified noise is frightening. Identification reduces fear -relief
I-4 Stepped on a twig ... stung with fright

I-8 A noise, breathing stops, feel small, insignificant, anxious, knees shake

I-9 It was a bird, owl (no need for fear)

II-6 I narrow pupils, sharpen ears trying to identify every sound.

II-7 Whenever I succeed in identifying a sound it puts me at ease: that is a bird, that is wind.

III-3 Noise ... provokes fear
4. Image seeing things, other people and they are not trusted. Identification reduces fear

I-14 Thought I saw someone... mistake (relief)

II-12 Frightened... paralysis through my limbs ... is someone standing there?

II-13 approach ... relieved ... there is nothing

II-14 worst... meet person here... mistrust . . cannot have good intentions.

5. Go faster, hurry up
I-10 caught myself going faster

II-5 I hurry along

II-10 Harder pedaling
Trying to make yourself small (I huddled up I-5) 
6. Heightened awareness, try to listen and watch more carefully (paradox: frightened by hearing \& seeing, see 3 \& 4 above)
I-3 Trying to make as little noise as possible

I-6 Looked carefully behind and alongside

I-11 Kept eyes, ears open

II-6 I narrow pupils, sharpen ears trying to identify every sound

II-11 I ride ... stay alert
Talk to yourself ... it doesn't help (I spoke to myself ... it was a little help I-7)
7. Behind you is unprotected
I-6 Looked carefully behind and alongside

II-8 There is my back unguarded

II-9 From behind I am vulnerable

II-10 Harder pedaling ... protect rear
8. Relief from anxiety, uncertainty to be back in light, among people
I-13 Relief to be past bushes

I-16 Money couldn't get me to go back

II-15 First light pole, glow, houses, deep breath and relief overcame me. Slow pace

II-16 Look behind now ... darkness recedes

II-17 If I met someone now, I am no longer afraid.
Don't look behind (but I still don't look II-9)

don't dare look to see. These variations help to enrich an understanding of the themes.

But we are not yet done with our analysis of "Afraid of the Dark." Another step that can be taken to reinforce or change the themes is to purposely introduce some variation into the description. For example, afraid in the dark in a different cultural setting-in Africa, in Asia, in Latin America; or in another physical setting-at home alone at night; or another social setting-afraid in the dark with others. The latter might be of particular interest because thus far our informants have all, spontaneously, discussed fear of the dark when alone. Maybe one doesn't have the same experience when someone else is there.

Here is a variation from someone who recalls being afraid in the dark with other people.

\section{Afraid in the Dark IV}

I'm not sure how well I'll be able to describe this experience. It was an unusual event. It only happened once and hopefully will never occur again. The fear was only there for a few seconds but I remember it even though it happened twenty years ago so it couldn't be too insignificant. 
I visited a cave, one of those caves which are advertised on billboards along the highway. "Unique largest grotto in the world, Jesse James hideout, etc." As we moved from room to room inside the cave the lights flashed on before us to show the way. There were 40 or more people on the tour so they had to be sure that everyone could see where they were going. When we were well into the cave and the tour, the guide told us, after showing us one "room," that he would turn the lights out so we could experience complete, absolute darkness; no light at all. Then he switched off the light.

Here the right words will be hard to find. When the lights went off the situation was transformed, physically, and socially. I was alone. The use of my eyes became worthless. The dark was inpenetrable. I tried to see, which is a very frustrating experience. There was nothing except the presence of nothing. I felt myself lost without visual points of reference and then a shock of fear went through my body, a feeling of warmth, the warmth of fright. Suppose the light broke down? Strangely enough I think that I actually resurrected that fear out of some perverse desire to badly scare myself.

After maybe two minutes, it was probably even a shorter time, the lights were turned on. The black murk disappeared and the clarity and weightlessness of the light returned. Darkness has a substance to it that light removes.

If we extract the forms from this description perhaps we can add to our earlier analysis.

1. When the lights went off the situation was transformed, physically and socially.

2. I was alone.

3. Tried to see-frustrating

4. Nothing except presence of nothing.

5. Felt myself lost-without reference

6. Black murk disappeared.

7. Darkness has substance.

Here we see a reinforcement of some common themes and also a variation on the source of fear. A paradoxical yet very interesting and illuminating change occurs from a fear of the presence of unknown people when alone in the dark to a fear of being alone when you are with other people, of having the social and physical world so transformed that you become afraid that they will be gone for good.

The theme of enveloping darkness is reinforced in this account as is the heightened awareness; these themes can be seen in the effort the informant expended at trying to penetrate the dark, and in the relief light brings when the episode is over.

Description IV adds an item to our list of variations, "being with others in the dark is still to be alone and fearful." What that has to do with fearing other people, with feeling small, with hurrying up, with the anxiety of anticipation, we are not quite sure but we think there is more here to be pursued. Also there is an interesting new suggestion about making oneself afraid in the dark. No one had mentioned that in the other examples. That too seems a good item 
for the list of variations. We need to go further, examining more descriptions and discussing to see whether it deserves to stay there or whether it is only at certain times we seek to scare ourselves.

Suggestion IV: Try putting the experience in a different context, a different situation. In other words, consider a phenomenological variation. Often, that gives a sharper picture of the shared aspects of the lived experience.

\section{Other Information}

There is no reason for you to limit your sources of information to the originally collected group of descriptions. We've gone to a novel Tom Sawyer for another example of being afraid in the dark. There are other literary examples about being afraid in the dark but few better than this one.

So he lay still and stared up into the dark. Everything was dismally still. By and by, out of the stillness little, scarcely perceptible noises began to emphasize themselves. The ticking of the clock began to bring itself into notice. Old beams began to crack mysteriously. The stairs creeked faintly. Evidently spirits were abroad. A measured muffled snore issued from Aunt Polly's chamber. And now the tiresome chirping of a cricket that no human ingenuity could locate, began. Next the ghostly ticking of a death-watch in the wall at the bed's head made Tom shudder-it meant that somebody's days were numbered. Then the howl of a far off dog rose on the night air and was answered by a fainter howl from a remoter distance. Tom was in agony.

This description provides support for some of the already identified themes. The heightened awareness, particularly of sounds, is important in this account. But there is something new here to ponder. Tom experiences the sounds as out there and the description suggests they have a will of their own. "The noises emphasize themselves": it is the clock which ticks and the stairs that creek and at the end of all this the conclusion that Tom draws, "Evidently spirits were abroad." Tom believes in the power of the invisible spirits who are abroad in the dark. He attributes meaning to the ticking of a "death-watch." Darkness, sounds, spirits and death, "Tom was in agony."

The attribution of unidentified will to sounds which are only remarkable in the dark is a theme which is well worth considering. It probably isn't only Tom's experience, but we would have to go further to see whether anyone else has ever had this feeling, that spirits are alive in the dark. Perhaps this is just the imaginings of a child, whereas adults see figures of people.

Suggestion V: Fill out the descriptions with new materials from poems, novels, diaries, folk tales, pictures, tape recordings, observations, interviews, et al. Be careful with this material. The question is not, how pretty is it, rather does it give an adequate descriptive picture of the lived experience? 
Information about being afraid in the dark may be found also in survey or experimental research. Don't overlook these data. Lived experience is the broadest of categories. It encompasses all of the experiences that we have. The general picture drawn in the descriptive-phenomenological analysis can be supplemented by narrowly focused studies.

\section{A Short Summary Essay}

Here is a short summary essay of the sort you might write after completing a phenomenological research.

\section{Being Afraid in the Dark}

Is there someone who hasn't known the "sting of fright" when a sudden noise appeared from the dark; or when the shadows seemed to reveal a human shape? Who hasn't breathed a sigh of relief when the lights went on to reveal the familiar and safe surroundings of one's own room?

We asked numerous people to recall for us an experience they had had of being frightened in the dark. All of them could do so. We took their descriptions and analyzed them to find similarities in reaction and circumstance.

We were able to identify eight common themes in the descriptions of our informants. That is not to say that all informants gave evidence of every theme in their description. It is to say that we were able to discern common patterns of meaning across several of the accounts and that these patterns made sense to us as statements about the meaning of "being afraid in the dark."

We have attempted to be true to the phenomenon-the experience of fear in the dark-but decisions about the meaning of experience do reflect the researcher's "reading" of the data. Other researchers might reflect a different emphasis. We are confident nevertheless that our different readings would be like two accounts of the same event rather than of two different occurrences. As in any study the only way to be sure is for readers to investigate the phenomenon for themselves.

The eight themes:

1. There is anxiety beforehand.

2. Darkness is enveloping.

3. Unidentified noises are frightening. Identification reduces fear.

4. Imagine seeing things, other people and they are not trusted. Identification reduces fear.

5. Go faster, hurry up.

6. Heightened awareness, try to listen and watch more carefully.

7. Behind you is unprotected.

8. Relief from anxiety, uncertainty, to be back in light among people.

We can begin by asking several simple questions about being afraid in the dark to see whether we have the answers from our informants.

Is it the dark which frightens or something else which is associated with the dark? The answer seems to be that both is the case. The absence of light is at the heart of being afraid. We are anxious in anticipating, and feel relief upon leaving the dark. A young woman who must go through a dark wood to get home is not happy at the prospect and full of relief to be back in the familiar surroundings where it is light. 
It is the dark which transforms familiar objects into fearful things. Shadowy shapes seem to be people and people are not to be trusted in the dark because they are up to no good. Noises appear and provoke fright until they are identified.

It is the dark which transforms the senses from normal to heightened awareness. Sounds and sights are carefully sought out. Everything strange needs to be perceived and a great deal that is seen and heard is strange. The dark world is full of new sights and sounds which must be named, before they become part of the familiar, safe world.

The dark is close, enveloping, almost physical in the way it encloses the body. The absence of the ability to see and identify things is felt like a blanket around the entire body. It is a blanket which cannot be removed except by light.

What do people do to overcome their fear?

They hurry up, talk to themselves, try to identify every strange sight and sound and never look back. In spite of these efforts time seems to go more slowly. People continue to feel themselves alone. The world of the dark persists in its strangeness with sounds that come from the abyss and formless shapes that seem human.

The struggle against the dark is a battle with peaks of anxiety and valleys of relative calm. One is no sooner over one fear than another unidentified something appears to be dealt with. Suspicion seems to predominate in darkness.

This suspicion can be seen in the fear of what lies behind your back. There is the feeling that something unidentified and strange lurks there but you don't look. Why? Because turning around does not change the fact that your back is exposed. It only changes the direction in which the back faces. In addition turning around to check impedes progress toward the real goal-the light. Being sure that there is nothing behind only creates a small reduction in the fear and that is only temporary.

This suspicion which appears with the darkness reveals the power of experience in consciousness and consciousness in experience. The "objective" darkness does not cause fear the way bad food causes a stomach ache. It creates conditions in which the fear of an unknown, unseen world full of dangerous threatening things comes to life in experience. These fears are as real as the darkness.

Can anything be done about fear of darkness?

First we can recognize that most of us are afraid at some time or other and that darkness has the effect of heightening our fears. These fears are as real as any other human emotion.

In dealing with children it is important to understand that fear and darkness go together. A child afraid in the dark can also be said to be afraid of the dark. The dark transforms familiar surroundings into unfamiliar and dangerous sights and sounds and it also envelopes and encloses eyes and body. It doesn't help to show a child by turning on the light that there is "nothing there" because once the light is off again "it" reappears.

It may be hopeful to discuss fear of darkness in school. Children can write their own descriptions of "being afraid in the dark" as can the teacher. It helps to show that you are not afraid alone and in addition a topic like this--which touches almost everyone-is interesting because it deals with a shared and powerful experience. 


\section{The Consequences for Action}

Research in education can lead to helpful action. This does not mean that every study must identify consequences but we do suggest that research into the meaning of experience for teachers, children, and parents has the potential to be valuable when time comes to make decisions about teachers, parents, and children. We mentioned at the start of this chapter that planners could use the reactions of those who must live with their decisions to make better choices. If for example a school principal is about to introduce a schedule change, a new regulation, or a new curriculum, a better decision is likely to result if teachers, pupils, and parents are studied to see what their experiences are in the present situation. Too often we assume that we know the meaning of experiences for others. But the everyday meaning of an experience for parents, for pupils, and for teachers may be different for each. Learning more about the meanings of the experience should be helpful.

Let's see what happens if we go back to being afraid in the dark. What does our provisional analysis suggest that might be helpful? Immediately, one thing comes to mind. Adults ought to be more understanding of children's fear of the dark. Why? Because, the dark is a scary place. It makes you feel alone and it makes all kinds of sounds come out that you didn't notice before and you see things sometimes too.

Who hasn't heard a mother or father comfortably seated in the living room reply to the child's cry, "Daddy, I'm afraid; it's dark," with "Go to sleep there is nothing to be afraid of." Sometimes parents even go in, turn on the light and show the child that there is nothing to be afraid of. That is no solution at all. It doesn't respond to the problem. The fear is in the murky, surrounding dark. It isn't in the light. Turning on the light doesn't show anybody anything.

As a general rule studies of experience have the value of changing that other person's "irrational," "annoying," actions into rational, sensible, understandable ones. Where this is true applications flow naturally from results.

Suggestion VI: Phenomenological research is done with an eye to the consequences for action. Based on the research results, try to formulate recommendations that might lead to more possibilities for human autonomy, a better situation for those on whom a decision is to be visited. Knowledge of history can help to suggest directions for action.

A final word about writing. Language is the basis for understanding even in the scientific world. Because language is so important, we urge you to say what you want to say when you write; let your meaning come through loud and clear, and feel free to ignore the prescriptions and proscriptions that are often associated with science writing. If it seems appropriate to you to use the pronoun "I" then use it; 
there's no reason to refer to yourself through some contortion like "the present researcher" in service of a crazy notion of objectivity. Similarly, if you believe something to be true or false, then say so; you don't need to write about your research as if you were reporting results of a statistical test. Forget about the prose some scientists feel obliged to use and eschew senseless writing like this: "No difference is expected between the outcomes of treatment A and B," when in fact the whole literature review led to the opposite expectation. It is part of the craft of research to use language with care and precision; your language must make sense to you and to your readers. The demands of good language usage are difficult enough without erecting artificial barriers to clear prose out of a misguided belief that "scientific method" calls upon authors to be unclear. To write is to learn about the adequacy or inadequacy of your thoughts. Poor writing, obscure writing, statistical gobbledygook, teaches you little or nothing about those thoughts. If there is no struggle by the writer to be clear, or we might again use the word honest, then there is likely to be little benefit to the scientific community and no benefit to the community at large in the results.

When reports are badly written, no one wants to read them. And it is a sad reality that because of poor writing, many dissertations, particularly those done by education students, will never again be read after the committee has finished with them. The work that went into these dissertations was a waste of everyone's time, particularly the "subjects" who agreed to be studied. If writing well were an important criterion for judging the adequacy of research we believe research would improve.

Suggestion X: After you have made preliminary analyses and again when you have completed the written report ask your informants to read and comment on the accuracy of your account. Struggling to say everything as clearly and accurately as possible is at the heart of the research enterprise.

In the conduct of phenomenological research the analysis of written material usually looms as a formidable task. We have found the procedures described in this article helpful in showing how to begin. We do not offer them as a method to be followed slavishly but rather as an example of one systematic way to proceed toward understanding meaning in textual material whether gathered directly as we have done here or from interviews or observation. In addition by analyzing material in class questions which inevitably arise in the course of research present themselves with the force of necessity enabling everyone to see that choices must be made in the conduct of research. These dilemmas are a fine stimulus to important discussions.

We hope these ideas will be useful to you in getting your own work started. We will be most pleased if you quickly move away from our advice to develop effective ways of your own. 


\section{Notes}

1. This article is adapted from a chapter in A Handbook for Phenomenological Research in Education written during 1978/79 with support for the senior author from the Government of the Netherlands through the Zuiver Wetenschappelijk Onderzoek Bureau voor (Scholarly Research) Ministry of Education. We gratefully acknowledge that support. The Handbook is currently published as a monograph by the School of Education, The University of Michigan. 